\title{
The burden of neck pain in Brazil: estimates from the global burden of disease study 2019
}

Lucas de Melo Castro Deligne ${ }^{1}$, Maria Clara Brant Rocha ${ }^{1}$, Deborah Carvalho Malta ${ }^{2}$, Mohsen Naghavi ${ }^{3}$ and Valéria Maria de Azeredo Passos ${ }^{1,4^{*}}$

\begin{abstract}
Background: This study analyzed neck pain estimates in Brazil and its states between 2000 and 2019, in view of the country's lacking epidemiological data.

Methods: An analysis was performed of the GBD 2019 estimates by location, sex, and age, per 100,000 population, with uncertainty intervals ( $95 \%$ UI). Brazilian estimates were compared to global, Mexican, English, and American rates.

Results: Global, Brazilian, and Mexican prevalence numbers were statistically homogeneous and stable in the period. Throughout the period analyzed in the study, Brazilian neck pain prevalence (2241.9; 95\%UI 1770.5-2870.6) did not show statistical differences when compared to global (2696.5; 95\%UI 2177.0-3375.2) or Mexican (1595.9; 95\%UI 1258.9-2058.8) estimates. Estimates observed in the USA (5123.29; 95\%UI 4268.35-6170.35) and England (4612.5; 95\%UI 3668.8-5830.3) were significantly higher. In 2019, when compared to the USA and England, agestandardized prevalences were lower globally, in Brazil, and in Mexico. Prevalences in Brazilian states were similar, being that Roraima (1915.9; 95\%UI 1506.5-2443.1) and the Federal District (1932.05; 95\%UI 1515.1-2462.7) presented the lowest and highest values respectively. The exception was the state of São Paulo (3326.5; 95\%UI 2609.6-4275.5). There was no statistical difference by sex, but the prevalence tended to increase with aging. In 2019, the Brazilian prevalence was 2478.6 (95\% UI 1791.0-3503.8), 5017.2 (95\%UI 3257.26-7483.8), and 4293.4 (95\% UI 2898,8-6343.9), for those aged 15 to 49,50 to 69, and 70+ years. There was no statistical difference among the YLDs in all locations and times.
\end{abstract}

\footnotetext{
* Correspondence: passos.v@gmail.com

${ }^{1}$ Faculdade Ciências Médicas de Minas Gerais, Belo Horizonte, Minas Gerais, Brazil

${ }^{4}$ School of Medicine, Universidade Federal de Minas Gerais, Belo Horizonte, Minas Gerais, Brazil

Full list of author information is available at the end of the article
}

(c) The Author(s). 2021 Open Access This article is licensed under a Creative Commons Attribution 4.0 International License, which permits use, sharing, adaptation, distribution and reproduction in any medium or format, as long as you give appropriate credit to the original author(s) and the source, provide a link to the Creative Commons licence, and indicate if changes were made. The images or other third party material in this article are included in the article's Creative Commons licence, unless indicated otherwise in a credit line to the material. If material is not included in the article's Creative Commons licence and your intended use is not permitted by statutory regulation or exceeds the permitted use, you will need to obtain permission directly from the copyright holder. To view a copy of this licence, visit http://creativecommons.org/licenses/by/4.0/ The Creative Commons Public Domain Dedication waiver (http://creativecommons.org/publicdomain/zero/1.0/) applies to the data made available in this article, unless otherwise stated in a credit line to the data. 
Conclusions: Brazil is going through a fast-paced process of populational aging; a higher prevalence of neck pain in middle-aged individuals and the elderly highlights the need for lifelong prevention initiatives. The higher rates observed among higher-income populations and the homogeneity of the Brazilian estimates suggest a lack of robust epidemiological data in lower-income countries.

Keywords: Neck pain, Burden of disease, Prevalence, Years lived with disability, Disability-adjusted life years

\section{Introduction}

Musculoskeletal diseases are the main causes of disability among adults $[1,2]$. Much of this disability burden is associated with populational aging, but also with behavioural and work-related risk factors [3]. Among musculoskeletal diseases, neck pain is the second most common cause of disability, second only to low back pain [4].

From a global perspective, neck pain has a point prevalence of $14.4 \%$, while the mean lifetime prevalence is $23.1 \%$ [5]. The 12 -month prevalence estimates vary from 21 to $42 \%$ among children and adolescents to 30 to $50 \%$ among adults and the elderly [6]. In Brazil, in 2017, this prevalence among adults was estimated at 20.3\% [7].

Neck pain is a complex condition, in which the association of individual, ergonomic, socio-cultural and psychosocial risk factors contributes to its occurrence and chronicity [8]. The main individual factors are age, sex, increased body mass index and smoking $[9,10]$. Among the environmental factors are those related to ergonomics, such as strenuous physical activity, use of force and vibration, improper posture and repetitive movements [6]. Previous history of neck and low back pain, poor health care and psychosocial problems such as job dissatisfaction, stress, anxiety and depression are other factors related to neck pain [10].

The economic impact of neck pain is significant and includes costs related to treatment, decreased productivity, non-attendance to work and social security [11]. In the USA, neck pain was responsible for 16 million medical consultations in 2010 [12]; in 2016, health costs for neck and low back pain diagnosis and treatment were estimated at 134 billion dollars [13]. In 2012, neck pain was responsible for job absences of 25.5 million Americans, who missed an average of 11.4 days of work [1]. Approximately three out of five European workers experienced symptoms of musculoskeletal pain in 2015, with neck and upper limbs pain accounting for $41 \%$ of the complaints [14]. In Brazil, neck pain was responsible for $7.2 \%$ of disability pensions granted to workers with musculoskeletal diseases [15].

The prevalence and the disability burden of neck pain in Brazil, both countrywide and at state level, have not yet been well defined, despite its likely impact on the economy and health of the Brazilian population. Therefore, this study aims to describe the prevalence and the burden of neck pain in Brazil and in the units of the federation in the years 2000, 2010 and 2019, as well as to draw parallels with the estimates of other countries for the same years.

\section{Methodology}

This descriptive study is based on the estimates from the Global Burden of Diseases Study (GBD) 2019, a systematic effort in descriptive epidemiology coordinated by the Institute for Health Metrics and Evaluation (IHME) at the University of Washington [16]. All estimates come from interdisciplinary approaches to enhance data quality and statistical modeling that have been already reported [16]. Since 2014, several investigations on the burden of disease were conducted by the GBD Brazil Network, which was created as a collaboration among the IHME, the Brazilian Ministry of Health, and a network of academic institutions led by the Federal University of Minas Gerais [17].

Neck pain is defined as pain located between the occipital region and the third thoracic vertebra, with or without irradiation to one or both upper limbs, which lasts more than 1 day and limits daily activities $[18,19]$. The definition of neck pain was based on the codification by the International Classification of Diseases, tenth edition (ICD-10): neck pain (M54.2); cervicocranial syndrome (M53.0); cervicobrachial syndrome (M53.1); back pain with cervical radiculopathy (M54.1); cervical spondylosis with radiculopathy (M47.2); cervical spondylosis with myelopathy (M47.1); cervical disc disorder (M50); cervicogenic headache (R51); sprain of ligaments of cervical spine (S13.4); and sprain of joints and ligaments of other parts of neck (S13.8) [20].

The GBD study uses three main indicators to calculate the burden of diseases: years of life lost due to premature mortality (YLLs), years lived with disability (YLDs) and the sum of YLLs to YLDs, which corresponds to the disability-adjusted life years (DALYs) [21]. Since neck pain is not a cause of death but a disabling condition, YLD and DALY estimates for neck pain are the same.

The disability weights used for estimating the diseases' YLDs are measured on a scale of zero to one, in which zero is equivalent to full health and one is equivalent to death. Disability weights were obtained from surveys conducted in several countries from different regions. The surveys used paired-comparison questions, in which 
the respondents considered two hypothetical individuals with different, randomly selected health conditions and were asked to indicate which individual they considered to be the healthiest. More methodological details are available elsewhere [22].

YLD due to neck pain is determined by multiplying the specific disease disability weight $(\mathrm{dw})$ by its prevalence in a given population (p) [23]:

$$
\begin{aligned}
\mathrm{YLD}= & \mathrm{DW} \times \mathrm{P}, \text { where } \mathrm{YLD}_{\mathrm{NP}} \\
= & (0.04 \times \text { Prevalence of mild acute sequelae }) \\
& +(0.221 \times \text { Prevalence of severe acute sequelae }) \\
& +(0.101 \times \text { Prevalence of mild chronic sequelae }) \\
& +(0.286 \times \text { Prevalence of severe chronic sequelae })
\end{aligned}
$$

The Socio-Demographic Index (SDI) is an indicator directly correlated to social economic standards used to compare different locations and times. It consists of a scale between zero and one, which aggregates the per capita income, educational level for those ages 15 and older, and fertility rate of women under 25 years of age. The higher the SDI, the greater the location's sociodemographic development is [18].

Neck pain prevalence and YLD estimates were analyzed for Brazil and all of its federative units. Global estimates and estimates for other countries were also used to compare the magnitude of national burden: 1) Mexico, a country in Latin America with an SDI similar to that of Brazil; 2) United States of America (USA), a country with one of the highest prevalence and YLD rates for neck pain; and 3) England, a developed country with a public health system similar to Brazil's. For each location, data were generated by both sexes, by standardized age, or by age group in the years 2000, 2010 and 2019.

Estimates were standardized by age to allow for a comparative analysis that takes into account changes due to population growth and aging. In addition, the position and changes in the classification rank of neck pain prevalence and YLDs were analyzed in the selected locations, in the same years of 2000, 2010 and 2019. To describe the degree of confidence in the metrics, the modeling process enables estimates to be calculated 1000 times and then distributed from the lowest to the highest value. The $95 \%$ uncertainty interval $(95 \% \mathrm{UI})$ is obtained from the 2.5 and 97.5 percentiles of this distribution, and it considers the error generated by the sample, the modeling, and the availability of data. All estimates are presented with their 95\% UI, and differences between estimates are statistically significant if the intervals are not coincident [16]. All estimates were produced by the Institute for Health Metrics and Evaluation (IHME) and available in the IHME website at: http:// ghdx.healthdata.org/gbd-results-tool [7]. The authors are responsible for describe and analyze these data.

The input data for neck pain in Brazil was based on three studies [7, 15, 24], covering the period from 2011 to 2017, two of them conducted in the state of São Paulo $[7,24]$. The data sources are available in the Global Health Data Exchange for each country (http://ghdx. healthdata.org/countries). Neck pain prevalence was estimated using the software DisMod-MR 2.1, by Bayesian meta-regression modeling tool [16]. The full list of articles used for statistical modelling can be found in the GBD 2019 Data Input Sources Tool [20]. To estimate prevalence, incidence, and YLDs, the Bayesian metaregression tool DisMod-MR 2.1 is used [16]. The modeling allows obtaining the best estimates, mainly of the localities such as Brazil, with few surveys and studies. In the GBD study, data are estimated in a homogeneous way, making it possible to compare neck pain between locations, by sex, and by age group.

The GBD Brazil study uses only secondary data, and it does not identify the individual or requires a free and informed consent form. The study was approved by the Ethics Committee of the Federal University of Minas Gerais (UFMG) under the registration $n^{\circ}$ $628,033,167.00005149$, according to the resolution no. 466/2012 of the National Health Council of Brazil.

\section{Results}

In Brazil, the age-standardized prevalence of neck pain in 2019 was 2241.9 (95\% IU 1770.6 - 2870.6) per 100,000 population. This means that in that year, about five million of the 211 million Brazilians presented with neck pain. Also in 2019, the global age-standardized prevalence was 2696.5 (95\% IU 2177 - 3357.2) per 100,000 population, similar to the Brazilian estimates. Throughout the study period, neck pain prevalence in Brazil did not show statistical differences when compared to global or Mexican estimates. On the other hand, the prevalence estimates of the USA and England were, in general, significantly higher (Table 1).

Most of the neck pain prevalence values remained stable in the locations and periods surveyed. Only in the USA there was a significant increase of the prevalence: $88.46 \%$ between 2010 and 2019, with the prevalence varying from 2718.6 (95\% IU 2386.3 - 3116.7) cases per 100,000 population to 5123.3 (95\% IU $4268.4-6170.4$ ) cases per 100,000 population in the period. Prevalence rates in Brazil showed an inverse trend when compared to the other locations, increasing between 2000 and 2010 but decreasing from 2010 to 2019 (Table 1).

The prevalence in all Brazilian federative units remained stable. In the year 2000 , these values varied from 1911.2 (95\% IU 1503.3-2436.2) per 100,000 population in Roraima to 1932.2 (95\% IU 1515.7-2462.3) per 
Table 1 Prevalence and YLD estimates from 2000 to 2019. Estimates from the GBD 2019

\begin{tabular}{|c|c|c|c|c|c|c|}
\hline \multicolumn{7}{|c|}{ Prevalence and YLD per 100,000 population ( $95 \%$ UI) } \\
\hline \multicolumn{7}{|c|}{ Both Sexes, Age-Standardized ${ }^{\mathrm{a}}$} \\
\hline & & 2000 & 2010 & 2019 & $\Delta v^{b}{ }^{b} 2000-2010$ & $\Delta \mathrm{v} \%$ 2010-2019 \\
\hline \multirow{2}{*}{$\begin{array}{l}\text { Global } \\
\text { SDI }^{\mathrm{C}} \\
(0.56-0.65)\end{array}$} & Prevalence & $2698.4(2167.3-3386.2)$ & $2614.5(2120.3-3276.1)$ & $2696.5(2177-3375.2)$ & -3.11 & 3.14 \\
\hline & YLD & $267.7(175.9-384.2)$ & $259.7(170.4-370)$ & $267.4(175.5-383.5)$ & -2.99 & 2.93 \\
\hline \multirow{2}{*}{$\begin{array}{l}\text { Brazil } \\
\text { SDI } \\
(0.54-0.64)\end{array}$} & Prevalence & $2252.3(1779.1-2883.3)$ & $2625(2077.2-3322.1)$ & $2241.9(1770.6-2870.6)$ & 16.55 & -14.59 \\
\hline & YLD & $221.9(145.80-322)$ & $259.1(170.1-373.1)$ & $221.7(145.4-322.6)$ & 16.77 & -14.43 \\
\hline \multirow{2}{*}{$\begin{array}{l}\text { Mexico } \\
\text { SDI } \\
(0.56-0.65)\end{array}$} & Prevalence & $1595(1258.5-2057.9)$ & $1595.6(1258.7-2058.6)$ & $1595.9(1258.9-2058.9)$ & 0.04 & 0.018 \\
\hline & YLD & $158.2(104.9-230.6)$ & $158(104.5-229.7)$ & $157.8(104.5-229.2)$ & -0.13 & -0.07 \\
\hline \multirow{2}{*}{$\begin{array}{l}\text { United States } \\
\text { SDI } \\
(0.85-0.91)\end{array}$} & Prevalence & 3984.8 (3195.3-5057) & $2718.6(2386.3-3116.7)$ & $5123.3(4268.4-6170.4)$ & -31.78 & 88.46 \\
\hline & YLD & $391(257.3-558.9)$ & $264.8(182.4-362.9)$ & $500.3(338.9-704.9)$ & -32.28 & 88.94 \\
\hline \multirow{2}{*}{$\begin{array}{l}\text { England } \\
\text { SDI } \\
(0.79-0.85)\end{array}$} & Prevalence & $5255.4(4218.8-6665)$ & 3816.5 (3069.3-4750.6) & 4612.6 (3668.8-5830.3) & -27.38 & 20.86 \\
\hline & YLD & 520.7 (344.2-754) & $377.9(250.1-543.1)$ & $457.7(309-651)$ & -27.41 & 21.10 \\
\hline
\end{tabular}

Source: IHME, GBD Study 2019, available at http://ghdx.healthdata.org/gbd-results-tool. ${ }^{\mathrm{a}} 95 \%$ UI: $95 \%$ uncertainty intervals, ${ }^{\mathrm{b}} \boldsymbol{\Delta} \mathrm{v} \%$-percentage change, ${ }^{\mathrm{c}} \mathrm{SDI}$ : Social-Demographic Index

100,000 population in Rio de Janeiro. In 2019, these values varied from 1915.9 (95\% IU 1506.5-2443.1) per 100,000 population in the state of Roraima to 1932.1 (95\% IU 1515.1-2462.7) per 100,000 population in Distrito Federal. The only exception occurred in the state of São Paulo, with prevalence values of 3325.7 (95\% IU 2608.9 - 4274.5), 3698.6 (95\% IU 3009.8 - 4592.2), and 3326.5 (95\% IU 2609.7 - 4275.5) per 100,000 population in 2000, 2010, and 2019 respectively (Table 2 ).

The annual change in neck pain prevalence estimates in Brazil was $16.55 \%$ between 2000 and 2010 and $14.59 \%$ between 2010 and 2019. In the state of São Paulo, this variation was $11.21 \%$ between 2000 and 2010 , and $-10.06 \%$ between 2010 and 2019. The average variation among Brazilian states was $20 \%$ between 2000 and 2010 and $-16 \%$ between 2010 and 2019. Although there is a difference between these variations, the magnitude of the curves for prevalence patterns in Brazil, the state of São Paulo, and the rest of the states was similar.

Table 3 shows 2019 global prevalence estimates of neck pain by sex and age groups, as well as agestandardized estimates for the countries evaluated. The prevalence is statistically higher for women in the USA, with the same trend occurring in the other countries. In Brazil, in 2019, the prevalence was 5376 (95\% IU 3495.78035.3 ) per 100,000 population among women and 3611.2 (95\% IU 2994.3-6999.1) per 100,000 population among men.

The global estimates show that, worldwide, aging was associated with a significant increase in neck pain prevalence. In 2019, there was a statistical difference in the global prevalence of neck pain for both sexes in the age group of 15 to 49 years, where the estimates were 2770.4 (95\% IU 2027.9 - 3851.4) per 100,000 population; in the age group of 50 to 69 years, where the estimates were 6064.2 (95\% IU 4070.1 - 9132.7) per 100,000 population; and in the age group of 70 years and older, with prevalence estimates of 5971.6 (95\% IU 4080 - 8621.7) per 100,000 population. However, when assessing the data in the countries evaluated, with the exception of the USA, there was only a tendency for this increase in prevalence with aging (Table 3 ).

Neck pain was the ninth clinical condition with the highest disability burden among the 369 diseases assessed by the GBD study in 2019, with a global agestandardized rate of 267.4 YLD (95\% IU 175, 5-383.5) per 100,000 population. In Brazil, in 2019, it represented the sixteenth clinical condition with the greatest impact on the population health, with a standardized rate for YLD of 221.7 (95\% IU 145.4-322.6) per 100,000 population. Contrary to the prevalence estimates, there was no statistical difference between the YLD values comparing Brazil, Mexico, the USA and England in 2010 and 2019. According to the estimates presented in Table 2, the USA and England had, with the exception of the year 2000, a trend of higher YLD rates, while Brazil and Mexico tended to lower values that were closer to the global numbers.

The age-standardized YLD rates were very similar among the Brazilian states. The state of São Paulo showed a trend to a higher burden of disability, with 328.5 YLD (95\% IU 216.3-476.6) per 100,000 population in 2019, but with coincident confidence intervals.

\section{Discussion}

This study shows a similar prevalence of neck pain among the global and countries with lower SDI (Brazil and Mexico), in contrast to higher estimates in countries 
Table 2 Prevalence and YLD estimates in Brazilian Federative Units from 2000 to 2019. Estimates from the GBD Study 2019 Prevalence and YLD per 100,000 population (95\%UI)

Brazil, Both Sexes, Age-Standardized

2000

Prevalence

YLD

Prevalence

YLD

Prevalence

YLD

Prevalence

YLD

Prevalence

YLD

Prevalence

YLD

Prevalence

YLD

(0.58)

\section{Northeastern States}

Alagoas
SDI
$(0.52)$
Bahia
SDI
$(0.56)$
Ceará
SDI
$(0.56)$

(0.56)

Maranhão

SDI

(0.44)

Paraíba

SDI

(0.55)

Pernambuco

SDI

(0.57)

PDI

(0.51)

Rio Grande do Norte SDI

(0.58)

Sergipe

SDI

(0.58)
Prevalence

YLD

Prevalence

YLD

Prevalence

YLD

Prevalence

YLD

Prevalence

YLD

Prevalence

YLD

Prevalence

YLD

Prevalence

YLD

Prevalence

YLD
1922.5 (1510.6-2450.9)

189 (124.4-275.4)

1919.4 (1508.8-2445.5)

189.7 (124-275.6)

1919.6 (1509-2446.8)

190.1 (124.9-276.8)

1919 (1508.9-2446)

189.4 (124.4-275.6)

1911.5 (1502.7-2438.2)

$188.5(124.1-274.1)$

1911.2 (1503.3-2436.2)

$188.4(124.4-274.3)$

1915.1 (1505.9-2442.1)

$188.9(124.8-275.7)$

226.2 (146.9-326.5)

227.5 (147.6-328.4)

2293.7 (1781-2968.2)

226.9 (147.1-329.7)

2287.8 (1776-2962.1)

226 (146.4-325.1)

2286.7 (1774.9-2961)

225.6 (145.2-326.1)

189

$$
189
$$

A v\% 2000-2010

v\% 2010-2019

$-16.24$

$-16.07$

$-16.21$

$-16.02$

$-16.25$

$-16.25$

$-16.24$

$-16.08$

$-16.11$

$-16.06$

$-16.21$

$-16.07$

$-16.13$

$-16.08$

19.77

$-16.34$

$-16.20$

$-16.32$

$-16.21$

$-16.39$

$-16.23$

$-16.26$

$-16.17$

$-16.42$

$-16.28$

$-16.43$

$-16.43$

$-16.37$

$-16.23$

$-16.4$

$-16.3$

$-16.35$

$-16.27$

Center-Western States

Goias

SDI

(0.63)
Prevalence 19

YLD
$189.3(126-274.5)$
2299.5 (1785.5-2978.5)

$226.9(147.8-326.9)$
1924.6 (1511.6-2453.2) 19.65

$190.3(125-277.8)$

19.84

$-16.3$

$-16.10$ 
Table 2 Prevalence and YLD estimates in Brazilian Federative Units from 2000 to 2019. Estimates from the GBD Study 2019 (Continued)

\begin{tabular}{|c|c|c|c|c|c|c|}
\hline \multicolumn{7}{|c|}{ Prevalence and YLD per 100,000 population (95\%UI) } \\
\hline \multicolumn{7}{|c|}{ Brazil, Both Sexes, Age-Standardized } \\
\hline & & 2000 & 2010 & 2019 & $\Delta \mathrm{v} \%$ 2000-2010 & $\Delta \mathrm{v} \%$ 2010-2019 \\
\hline \multirow{2}{*}{$\begin{array}{l}\text { Distrito Federal } \\
\text { SDI } \\
(0.78)\end{array}$} & Prevalence & $1931(1515-2462.2)$ & $2311.8(1796.6-2996)$ & $1932(1515.1-2462.7)$ & 19.72 & -16.43 \\
\hline & YLD & $190.1(125.9-278.4)$ & $228.3(150-330.8)$ & $191.3(126-277.7)$ & 20.06 & -16.20 \\
\hline \multirow{2}{*}{$\begin{array}{l}\text { Mato Grosso } \\
\text { SDI } \\
(0.64)\end{array}$} & Prevalence & $1913.2(1503.7-2439.4)$ & $2288.6(1776.7-2962.5)$ & $1918.8(1508.7-2446.3)$ & 19.63 & -16.16 \\
\hline & YLD & $188.7(123.9-274.5)$ & $226.2(149.6-329.7)$ & $189.9(124.6-276.7)$ & 19.89 & -16.06 \\
\hline \multirow{2}{*}{$\begin{array}{l}\text { Mato Grosso do Sul } \\
\text { SDI } \\
(0.64)\end{array}$} & Prevalence & $1920.8(1509.5-2450.1)$ & $2298.4(1784.5-2977.1)$ & $1923.8(1511.2-2452.3)$ & 19.66 & -16.30 \\
\hline & YLD & $189(125-273.5)$ & $226.2(149.4-325.7)$ & $189.9(125.6-275.6)$ & 19.69 & -16.05 \\
\hline \multicolumn{7}{|l|}{ Southeastern States } \\
\hline \multirow{2}{*}{$\begin{array}{l}\text { Espirito Santo } \\
\text { SDI } \\
(0.66)\end{array}$} & Prevalence & 1924.7 (1511.4-2453.5) & 2302.5 (1788.8-2981) & $1926.1(1512.7-2454.5)$ & 19.63 & -16.35 \\
\hline & YLD & 189.8 (125.4-275.5) & $227.5(148.3-329.6)$ & $190.6(124.9-278.7)$ & 19.90 & -16.22 \\
\hline \multirow{2}{*}{$\begin{array}{l}\text { Minas Gerais } \\
\text { SDI } \\
(0.64)\end{array}$} & Prevalence & 1925.7 (1512.2-2454.3) & $2302.6(1789-2981.1)$ & $1925.8(1512.4-2454.3)$ & 19.58 & -16.37 \\
\hline & YLD & $190.1(124.9-275.4)$ & $227.7(148.5-329.8)$ & $190.8(126.1-276.7)$ & 19.80 & -16.19 \\
\hline \multirow{2}{*}{$\begin{array}{l}\text { Rio de Janeiro } \\
\text { SDI } \\
(0.70)\end{array}$} & Prevalence & $1932.2(1515.7-2462.3)$ & $2311.4(1797-2993.4)$ & 1930.8 (1514.9-2460.3) & 19.63 & -16.47 \\
\hline & YLD & $191(126.2-276.3)$ & $228.9(149.5-330.8)$ & $191.4(126.1-277.8)$ & 19.84 & -16.38 \\
\hline \multirow{2}{*}{$\begin{array}{l}\text { São Paulo } \\
\text { SDI } \\
(0.70)\end{array}$} & Prevalence & 3325.7 (2608.9-4274.5) & 3698.6 (3009.8-4592.2) & 3326.5 (2609.7-4275.5) & 11.21 & -10.06 \\
\hline & YLD & $326.6(214.6-474.7)$ & $364.1(241.7-518.6)$ & 328.5 (216.3-476.6) & 11.45 & -9.77 \\
\hline \multicolumn{7}{|l|}{ Southern States } \\
\hline \multirow{2}{*}{$\begin{array}{l}\text { Paraná } \\
\text { SDI } \\
(0.66)\end{array}$} & Prevalence & $1924.5(1511.5-2453.9)$ & $2303.2(1789-2983.1)$ & 1926.7 (1512.8-2455.7) & 19.68 & -16.34 \\
\hline & YLD & $189.8(124.7-274.2)$ & $227.5(148.6-330.1)$ & 190.9 (126.3-278.3) & 19.85 & -16.09 \\
\hline \multirow{2}{*}{$\begin{array}{l}\text { Rio Grande do Sul } \\
\text { SDI } \\
(0.68)\end{array}$} & Prevalence & 1928 (1513.6-2456.3) & 2305.5 (1792.1-2984) & $1927.1(1513.3-2455.5)$ & 19.58 & -16.41 \\
\hline & YLD & 189.9 (124.5-276.5) & $227.8(147.6-330.7)$ & $190.6(126.4-276)$ & 19.92 & -16.31 \\
\hline \multirow{2}{*}{$\begin{array}{l}\text { Santa Catarina } \\
\text { SDI } \\
(0.69)\end{array}$} & Prevalence & $1924.6(1511.9-2452.1)$ & $2301.4(1788.4-2978)$ & 1924.6 (1512.-2451.9) & 19.58 & -16.37 \\
\hline & YLD & $190.1(125.1-275.5)$ & $227.7(149.3-328.7)$ & $190.8(125.7-277.9)$ & 19.78 & -16.24 \\
\hline
\end{tabular}

Both sexes and age-standardized (A.S) from Brazilian federal units prevalences and YLDs rates in 2000, 2010 and 2019 , and percentage change ( $\boldsymbol{\Delta}$ v\%) from 2000 to 2010 and from 2010 to 2019. Social-Demographic Index (SDI) from 2019

with higher SDI (England and USA). Although generalization is not possible, other studies also showed a higher prevalence and burden of neck pain among countries with higher SDI $[5,23]$. On the other hand, population aging is increasing exponentially in countries with lower SDI, under conditions of low access to diagnosis and treatment of chronic-degenerative diseases [25]. Barriers to accessing health care and, consequently, receiving a diagnosis, may explain the underestimation of data in these low-income countries [26]. In 2013, a first Brazilian survey on spinal pain indicated an increase from $18.5 \%$ (95\%UI $17,8-19,1)$ (2013) to $21.6 \%$ (95\%UI 21-22.1) (2019), with subnational variation in 2019 from (13 95\%UI 1.6-15.7) in the Federal District, to 26\% (95\%UI 23.2-28.8) in Bahia. This survey indicates spinal pain affects about 34.3 million Brazilians, but data did not distinguish the specific local of spinal pain [27].
The annual change in prevalence and YLDs estimates of neck pain in Brazil and in all of its federative units did not follow the same patterns presented by the other countries. While global and Mexican estimates were stable over the period evaluated, Brazilian prevalence estimates increased between 2000 and 2010 and then decreased between 2010 and 2019. The opposite pattern was presented by countries with a higher SDI such as the USA and England. These differences can be mainly attributable to the methodologies and data sources used in the epidemiological studies performed in each location.

The stability and homogeneity observed in the global prevalence estimates, as well as for Brazil, and Mexico, suggest the absence of population-based prevalence studies. Likewise, most of the Brazilian federative units presented similar prevalence estimates 
Table 3 Prevalence of neck pain, by sex and age from 2000 to 2019. GBD 2019 estimates

\begin{tabular}{|c|c|c|c|c|c|c|c|c|}
\hline \multicolumn{9}{|c|}{ Prevalence per 100,000 population $\left(95 \% \mathrm{UI}^{\mathrm{a}}\right)$} \\
\hline \multicolumn{9}{|c|}{ By sex and age range, age-standardized } \\
\hline & & \multicolumn{3}{|l|}{ Male } & & \multicolumn{3}{|l|}{ Female } \\
\hline & & 2019 & $\begin{array}{l}\Delta v^{2} \%^{b} 2000- \\
2010\end{array}$ & $\begin{array}{l}\Delta \mathrm{v} \% \text { 2010- } \\
2019\end{array}$ & & 2019 & $\begin{array}{l}\Delta \text { v\% 2000- } \\
2010\end{array}$ & $\begin{array}{l}\Delta \mathrm{v} \% 2010- \\
2019\end{array}$ \\
\hline \multirow{5}{*}{$\begin{array}{l}\text { Global } \\
\text { SDI }^{\mathrm{C}} \\
(0.56-0.65)\end{array}$} & $\begin{array}{l}\text { Age } \\
\text { (Years) }\end{array}$ & & & & $\begin{array}{l}\text { Age } \\
\text { (Years) }\end{array}$ & & & \\
\hline & A.S & $\begin{array}{l}2352.3(1907.3- \\
2.951,9)\end{array}$ & -2.86 & 3.02 & A.S & $3031.8(2440.2-3.827,1)$ & -3.31 & 3.23 \\
\hline & $15-49$ & $2415(1759-3353.4)$ & -3.01 & 3.51 & $15-49$ & $3133.8(2297.4-4345.1)$ & -1.9 & 4.12 \\
\hline & $50-69$ & $5210.8(3485.7-7817.9)$ & -0.95 & 4.74 & $50-69$ & $\begin{array}{l}6885.3(4599.1- \\
10,306.2)\end{array}$ & -1.63 & 4.63 \\
\hline & $\geq 70$ & $\begin{array}{l}5344.1(3600.5- \\
7686.7)\end{array}$ & 0.08 & 4.53 & $>70$ & $6462.1(4461.7-9238.7)$ & -2.83 & 4.69 \\
\hline \multirow{5}{*}{$\begin{array}{l}\text { Brazil } \\
\text { SDI } \\
(0.54-0.64)\end{array}$} & $\begin{array}{l}\text { Age } \\
\text { (Years) }\end{array}$ & & & & $\begin{array}{l}\text { Age } \\
\text { (Years) }\end{array}$ & & & \\
\hline & A.S & $2080.8(1647.6-2657.6)$ & 14.60 & $-13,16$ & A.S & $2386.4(1871.5-3060.2)$ & 18.00 & -15.68 \\
\hline & $15-49$ & 2299 (1673.7-3254) & 20.26 & -8.07 & $15-49$ & $2653.6(1906.5-3770.1)$ & 23.38 & -10.13 \\
\hline & $50-69$ & $4611.2(2994.3-6999.1)$ & 17.86 & -15.25 & $50-69$ & 5376 (3495.7-8035.3) & 22.60 & -18.43 \\
\hline & $\geq 70$ & 3944.9 (2613.6-5820.3) & 9.80 & -8.93 & $>70$ & 4549 (3095.8-6719.4) & 12.83 & -12.19 \\
\hline \multirow{5}{*}{$\begin{array}{l}\text { Mexico } \\
\text { SDI } \\
(0.56-0.65)\end{array}$} & $\begin{array}{l}\text { Age } \\
\text { (Years) }\end{array}$ & & & & $\begin{array}{l}\text { Age } \\
\text { (Years) }\end{array}$ & & & \\
\hline & A.S & 1496.9 (1183.4-1889.6) & 0 & 0 & A.S & $1685.2(1333.2-2166.3)$ & 0 & 0 \\
\hline & $15-49$ & $1581(1142.8-2212)$ & 5.91 & 3.63 & $15-49$ & 1815 (1317.3-2578.4) & 7.27 & 4.34 \\
\hline & $50-69$ & $3234.1(2123.2-4862.9)$ & -0.019 & 0.071 & $50-69$ & 3645.5 (2405.4-5524) & -0.039 & 0.076 \\
\hline & $\geq 70$ & 2982 (1998.3-4376.5) & 0.0095 & 0.15 & $>70$ & 3401.7 (2237.6-4990.3) & -0.43 & -0.078 \\
\hline \multirow{5}{*}{$\begin{array}{l}\text { United } \\
\text { States } \\
\text { SDI } \\
(0.85-0.91)\end{array}$} & $\begin{array}{l}\text { Age } \\
\text { (Years) }\end{array}$ & & & & $\begin{array}{l}\text { Age } \\
\text { (Years) }\end{array}$ & & & \\
\hline & A.S & 4145.1 (3439.8-4972.2) & -21 & -8.48 & A.S & 6077.7 (5039.6-7365.9) & -9 & 3.14 \\
\hline & $15-49$ & 4305.6 (3363.3-5590) & -19.75 & -9.25 & $15-49$ & $7074.3(5518-9244.4)$ & -6.04 & 1.53 \\
\hline & $50-69$ & $8853(6306.5-12,529.6)$ & -22.69 & -10.83 & $50-69$ & $\begin{array}{l}11,888.48394 .4- \\
16,535.7\end{array}$ & -10.17 & 6.22 \\
\hline & $>70$ & $\begin{array}{l}9502.4(6954.3- \\
12,866.8)\end{array}$ & -21.93 & -6.25 & $>70$ & $\begin{array}{l}11,312.7(8286.5- \\
15,139.3)\end{array}$ & -18.59 & 0.16 \\
\hline \multirow{5}{*}{$\begin{array}{l}\text { England } \\
\text { SDI } \\
(0.79-0.85)\end{array}$} & $\begin{array}{l}\text { Age } \\
\text { (Years) }\end{array}$ & & & & $\begin{array}{l}\text { Age } \\
\text { (Years) }\end{array}$ & & & \\
\hline & A.S & 3944.3 (3130.5-4983.2) & -26.17 & 17.71 & A.S & 5276 (4205.2-6697) & -23.35 & 17.65 \\
\hline & $15-49$ & 4729.9 (3392.7-6424.5) & -34.8 & 30.85 & $15-49$ & $6484.2(4706.8-8814.4)$ & -30.52 & 30.69 \\
\hline & $50-69$ & $\begin{array}{l}7365.6(4794.8- \\
11,048.3)\end{array}$ & -18.21 & 5.44 & $50-69$ & $\begin{array}{l}9474.7(6180.2- \\
14,146.2)\end{array}$ & -20.14 & 7.33 \\
\hline & $\geq 70$ & 7351 (4920.9-11,069.5) & -17.08 & -3.25 & $>70$ & $\begin{array}{l}8844.8(6019.7- \\
12,806.3)\end{array}$ & -23.79 & -6.94 \\
\hline
\end{tabular}

Global, Brazilian, American and England prevalences and YLDs by sex, age-standardized (A.S) and age range rates in 2019, and percentage change ( $\Delta$ v\%) from 2000 to 2010 and from 2010 to 2019. Social-Demographic Index (SDI) from 2000 and from 2019

and variations between the years evaluated, with the notable exception of São Paulo. This result suggests a paucity of data source and scientific data in Brazil in this period, since among the three studies carried out in Brazil [7, 15, 24] two were carried out in São Paulo [7, 24].

According to the results, the prevalence of cervical pain in Brazil ranges from 20.3\% (95\% CI 18-22.7\%) to 
$22 \%$ (95\% CI 19.3-25\%). The third study, carried out in the state of Rio de Janeiro, covered only among young adults, ages ranging from 18 to 21 years old, and presents a prevalence of $36 \%$ (95\% CI 28.4-44.3\%) [15]. The Brazilian national health surveys do not address specifically the neck pain. Methodological differences between theses studies and GBD estimates do not allow comparison of results.

Previous studies pointed out the higher prevalence rate of neck pain among women [9, 28, 29], and their lower tendency to recover from such pain [30], different from data of more recent studies [7, 23]. A higher prevalence of chronic spinal pain among women was also reported in Brazil [31]. GBD estimates in 2019 showed higher prevalence only among USA women, while the other studied countries did not present the same trend. These differences may represent different exposure to workrelated risk factors and sedentary life-style as well as different access to diagnosis in these countries.

The higher prevalence of neck pain among middleaged adults and elderly shows the importance of age as a risk-factor to of aging musculoskeletal diseases $[9,31-35]$. Studies have only shown a significant peak of point prevalence in the middle age [5, 23, 30, 34]. Younger men and women have a higher prevalence of neck pain, but recover more often from it than older individuals. The overall rates of recurrence and chronicity of neck pain are around 30 to $50 \%[8,36]$. This chronicity, added to the fact that it affects both sexes and begins at a younger age, make the burden of neck pain to be classified among the highest YLDs in Brazil and in the world [37].

Despite the prevalence of neck pain being statistically higher in the higher-income countries evaluated, the USA and England, this difference was not significant between the YLDs when compared to the estimates of Brazil.. This fact suggests that neck pain affects a younger population in Brazil, the long duration of the disease make the YDL similar to countries with a higher prevalence.

Despite the prevalence of neck pain is statistically higher in the higher SDI countries evaluated, this difference was not significant between the YLDs when compared to the estimates of Brazil. Musculoskeletal conditions are neglected in most national health surveys: among 170 national health surveys from different countries, only 37 cited cervical pain [38]. Besides, the different definitions of neck pain prevent the comparison [38]. The higher rates presented in the US are probably related to the inclusion of neck pain investigation in annual surveys since 2013, the availability of regular data providing more reliable information.

Low income is a risk factor for chronic spinal pain and is associated with a worse prognosis for chronic neck pain
[7, 31]. More recent studies have revealed a higher prevalence of chronic neck pain and a notable association with people with low education $[39,40]$. Thus, since the burden of the disease depends on the sum of the prevalence of the different spectra of the disease, which in the case of neck pain encompasses severity and chronicity, the fact that lower SDI countries have a YLD similar to that of higher SDI could be justified by a higher prevalence of chronic and severe neck pain in these locations.

The GBD Project systematically updates global and national estimates of the burden of several diseases, aiming to encourage detailed analysis for decision making at a local level. Regarding the scientific production using GBD estimates, the GBD Brazil Network has done several analyses that have resulted in the publication of two capstone papers and two journal supplements on the burden of several diseases [17]. This study presents the current Brazilian status of the burden of neck pain with the best available data. Considering Brazilian subnational diversity, obtaining reliable estimates is challenging. Our results emphasize the importance of the research on musculoskeletal diseases in the country, especially in the current context of economic and political crisis, with funding restriction [41].

This study presents as a strength the standardized methodology that enables comparisons between locations and times. On the other hand, it does not distinguish between the risk factors associated with the onset and recurrence of cervical pain, nor does it analyze the risk factors common to cervical pain, such as exposure to high-demand work, smoking history, psychological disorders, low educational level and a past history of cervical pain [42, 43], since these were not addressed by the GBD study.

Given the trend for population aging, greater investments in public health policies are necessary to avoid individual and financial losses. The results of this study can contribute to the understanding of the importance of neck pain and help improve the prevention and control of risk factors for chronic degenerative diseases programs. In addition, it highlights the importance of diagnosis, early treatment and adequate rehabilitation, which tend to reduce the disability generated by neck pain.

\section{Abbreviations}

A.S: Age-Standardized; DALY: Disability adjusted life years; DW: Disability weight; GBD: Global Burden of Diseases; ICD-10: International Classification of Diseases, tenth edition; IHME: Institute for Health Metrics and Evaluation; P: Prevalence; SDI: Socio-Demographic Index; UFMG: Federal University of Minas Gerais; UI: Uncertainty intervals; USA: United States of America; YLD: Years lived with disability; YLD ${ }_{N p}$ : YLD due to neck pain; YLL: Years of life lost due to premature mortality

\section{Acknowledgements}

We thank the IHME researchers and the Brazil Network team. We also thank Ms. Rita Espeschit for the English review and copyediting. 


\section{Authors' contributions}

Lucas M. C. Deligne, Maria Clara B. Rocha, and Valéria M. A. Passos contributed to the conceptualization, investigation, methodology, formal analysis, and writing of the original draft. Mohsen Naghavi contributed to the investigation, methodology, and review of the original draft. Deborah C Malta contributed to the conceptualization, and review of the original draft. The author(s) read and approved the final manuscript.

\section{Funding}

Bill \& Melinda Gates Foundation primarily funded the development of the GBD 2019 study database and methods. The Brazilian Ministry of Health facilitated access to data sources and was responsible for funding the study GBD Brazil, through the National Health Fund (Fundo Nacional de Saúde, Process No. 25000192049 / 2014-14). Neither institutions participated in the study design, data collection, analysis and interpretation or writing of the manuscript and submission for publication.

\section{Availability of data and materials}

Data we used in this article are publicly available online (http://ghdx. healthdata.org/gbd-results-tool).

\section{Declarations}

\section{Ethics approval and consent to participate}

The Institutional Review Board of the University of Washington approved the GBD study. There was no need to submit to this research to the local Institutional Review Boards, as data were obtained from a public domain secondary database, without nominal identification, in accordance with Decree No. 7,724, May 16, 2012 and Resolution 510, of April 7, 2016. The Institutional Review Board of the Universidade Federal de Minas Gerais approved the GBD Brazil study, under the protocol CAAE62803316.7.0000.5149. A consent to participate does not apply, as no individual patient data was collected.

\section{Consent for publication}

Not applicable.

\section{Competing interests}

The authors have no competing conflicts of interest regarding this manuscript.

\section{Author details}

'Faculdade Ciências Médicas de Minas Gerais, Belo Horizonte, Minas Gerais, Brazil. ${ }^{2}$ School of Nursing, Universidade Federal de Minas Gerais, Belo Horizonte, Minas Gerais, Brazil. ${ }^{3}$ Institute of Health Metrics and Evaluation, Washington University, Seattle, USA. ${ }^{4}$ School of Medicine, Universidade Federal de Minas Gerais, Belo Horizonte, Minas Gerais, Brazil.

Received: 4 March 2021 Accepted: 21 August 2021

Published online: 21 September 2021

\section{References}

1. The Impact of Musculoskeletal Disorders on Americans - Opportunities for Action. Bone and Joint Initiative USA. 2016.(http://www.bonea ndjointburden.org/docs/BMUSExecutiveSummary2016.pdf).

2. Theis KA, Roblin DW, Helmick CG, Luo R. Prevalence and causes of work disability among working-age U.S. adults, 2011-2013, NHIS. Disabil Health J. 2018;11(1):108-15. https://doi.org/10.1016/j.dhjo.2017.04.010 Epub 2017 Apr 25.

3. Blyth FM, Briggs AM, Schneider CH, Hoy DG, March LM. The global burden of musculoskeletal pain-where to from Here? Am J Public Health. 2019; 109(1):35-40. https://doi.org/10.2105/AJPH.2018.304747 Epub 2018 Nov 29.

4. March L, Smith EU, Hoy DG, Cross MJ, Sanchez-Riera L, Blyth F, et al. Burden of disability due to musculoskeletal (MSK) disorders. Best Pract Res Clin Rheumatol. 2014;28(3):353-66. https://doi.org/10.1016/j.berh.2014.08.002 Epub 2014 Nov 18

5. Hoy DG, Protani M, De R, Buchbinder R. The epidemiology of neck pain. Best Pract Res Clin Rheumatol. 2010;24(6):783-92. https://doi.org/10.1016/j. berh.2011.01.019.

6. Hogg-Johnson S, van der Velde G, Carroll LJ, Holm LW, Cassidy JD, Guzman J, et al. Bone and Joint Decade 2000-2010 Task Force on Neck Pain and Its
Associated Disorders. The burden and determinants of neck pain in the general population: results of the Bone and Joint Decade 2000-2010 Task Force on Neck Pain and Its Associated Disorders. Spine (Phila Pa 1976). 2008;33(4 Suppl):S39-51. https://doi.org/10.1097/BRS.0b013e31816454c8.

7. Genebra CVDS, Maciel NM, Bento TPF, Simeão SFAP, Vitta A. Prevalence and factors associated with neck pain: a population-based study. Braz J Phys Ther. 2017;21(4):274-80. https://doi.org/10.1016/j.bjpt.2017.05.005 Epub 2017 May 20.

8. Blanpied PR, Gross AR, Elliott JM, Devaney LL, Clewley D, Walton DM, et al. Neck pain: revision 2017. J Orthop Sports Phys Ther. 2017;47(7):A1-A83. https://doi.org/10.2519/jospt.2017.0302.

9. Fejer R, Kyvik KO, Hartvigsen J. The prevalence of neck pain in the world population: a systematic critical review of the literature. Eur Spine J. 2006; 15(6):834-48. https://doi.org/10.1007/s00586-004-0864-4 Epub 2005 Jul 6.

10. Croft PR, Lewis M, Papageorgiou AC, Thomas E, Jayson Ml, Macfarlane GJ, et al. Risk factors for neck pain: a longitudinal study in the general population. Pain. 2001;93(3):317-25. https://doi.org/10.1016/s0304-3959(01 )00334-7.

11. Borghouts JA, Koes BW, Vondeling H, Bouter LM. Cost-of-illness of neck pain in the Netherlands in 1996. Pain. 1999;80(3):629-36. https://doi.org/10.1016/ s0304-3959(98)00268-1.

12. United States Bone and Joint Initiative: The Burden of Musculoskeletal Diseases in the United States (BMUS), Third Edition, 2014. Rosemont, LL. ISBN: 978-0-9963091-0-3. Copyright @ 2018 by the United States Bone and Joint Initiative.

13. Dieleman JL, Cao J, Chapin A, Chen C, Li Z, Liu A, et al. US health care spending by payer and health condition, 1996-2016. JAMA. 2020;323(9):86384. https://doi.org/10.1001/jama.2020.0734.

14. OSHA UE. Work-related musculoskeletal disorders: prevalence, costs and demographics in the EU; 2019. https://doi.org/10.2802/66947.

15. Meziat Filho N, Coutinho ES. Azevedo e Silva G. association between home posture habits and low back pain in high school adolescents. Eur Spine J. 2015;24(3):425-33. https://doi.org/10.1007/s00586-014-3571-9 Epub 2014 Sep 12.

16. GBD 2019 Diseases and Injuries Collaborators. Global burden of 369 diseases and injuries in 204 countries and territories, 1990-2019: a systematic analysis for the Global Burden of Disease Study 2019. Lancet. 2020;396(10258):1204-22. https://doi.org/10.1016/S0140-6736(20)30925-9 Erratum in: Lancet. 2020 Nov 14;396(10262):1562.

17. Malta DC, de Azeredo Passos VM, Machado ÍE, Marinho Souza MF, Ribeiro ALP. The GBD Brazil network: better information for health policy decisionmaking in Brazil. Popul Health Metrics. 2020;18(Suppl 1):23. https://doi.org/1 0.1186/s12963-020-00224-1.

18. Fejer R, Hartvigsen J. Neck pain and disability due to neck pain: what is the relation? Eur Spine J. 2008;17(1):80-8. https://doi.org/10.1007/s00586-0070521-9 Epub 2007 Oct 23.

19. Guzman J, Hurwitz EL, Carroll L, Haldeman S, Côté P, Carragee EJ, et al. Bone and Joint Decade 2000-2010 Task Force on Neck Pain and Its Associated Disorders. A new conceptual model of neck pain: linking onset, course, and care: the Bone and Joint Decade 2000-2010 Task Force on Neck Pain and Its Associated Disorders. Spine (Phila Pa 1976). 2008:33(4 Suppl):S14-23. https://doi.org/10.1097/BRS.0b013e3181643efb.

20. IHME: http://www.healthdata.org/sites/default/files/files/data_for_download/ 2012/HME_GBD2010_CauseListandICD.pdf. Acessed 20 Jun 2020.

21. Murray CJL, Lopez AD, World Health Organization, World Bank \& Harvard School of Public Health. In: Murray CJL, Lopez AD, editors. The Global burden of disease : a comprehensive assessment of mortality and disability from diseases, injuries, and risk factors in 1990 and projected to 2020 : summary: World Health; 1996.

22. Salomon JA, Haagsma JA, Davis A, de Noordhout CM, Polinder S, Havelaar $\mathrm{AH}$, et al. Disability weights for the global burden of disease 2013 study. Lancet Glob Health. 2015;3(11):e712-23. 26475018. https://doi.org/10.1016/ S2214-109X(15)00069-8.

23. Safiri S, Kolahi AA, Hoy D, Buchbinder R, Mansournia MA, Bettampadi D, et al. Global, regional, and national burden of neck pain in the general population, 1990-2017: systematic analysis of the global burden of disease study 2017. BMJ. 2020;368:m791. https://doi.org/10.1136/bmj.m791.

24. Depintor JD, Bracher ES, Cabral DM, Eluf-Neto J. Prevalence of chronic spinal pain and identification of associated factors in a sample of the population of São Paulo, Brazil: cross-sectional study. Sao Paulo Med J. 2016;134(5):37584. https://doi.org/10.1590/1516-3180.2016.0091310516. 
25. Hoy D, March L, Woolf A, Blyth F, Brooks P, Smith E, et al. The global burden of neck pain: estimates from the global burden of disease 2010 study. Ann Rheum Dis. 2014;73(7):1309-15. https://doi.org/10.1136/annrheumdis-2013-2 04431 Epub 2014 Jan 30

26. O'Donnell O. Access to health care in developing countries: breaking down demand side barriers. Cad Saude Publica. 2007:23(12):2820-34. https://doi. org/10.1590/s0102-311×2007001200003.

27. Malta DC, Oliveira MM, Andrade SSCA, Caiaffa WT, Souza MFM, Bernal RTI. Factors associated with chronic back pain in adults in Brazil. Rev Saude Publica. 2017;51(suppl 1):9s. https://doi.org/10.1590/\$1518-8787.2017051 000052

28. Cunha AC, Burke TN, França FJ, Marques AP. Effect of global posture reeducation and of static stretching on pain, range of motion, and quality of life in women with chronic neck pain: a randomized clinical trial. Clinics (Sao Paulo). 2008;63(6):763-70. https://doi.org/10.1590/s1807-59322 008000600010.

29. Paksaichol A, Janwantanakul P, Purepong N, Pensri P, van der Beek AJ. Office workers' risk factors for the development of non-specific neck pain: a systematic review of prospective cohort studies. Occup Environ Med. 2012; 69(9):610-8. https://doi.org/10.1136/oemed-2011-100459 Epub 2012 May 12.

30. Skillgate E, Magnusson C, Lundberg M, Hallqvist J. The age- and sex-specific occurrence of bothersome neck pain in the general population--results from the Stockholm public health cohort. BMC Musculoskelet Disord. 2012; 13:185. Published 2012 Sep 24. https://doi.org/10.1186/1471-2474-13-185.

31. Romero DE, Santana D, Borges P, Marques A, Castanheira D, Rodrigues JM, et al. Prevalence, associated factors, and limitations related to chronic back problems in adults and elderly in Brazil. Cad Saude Publica. 2018;34(2): e00012817. Portuguese, English. https://doi.org/10.1590/0102-311X00012817.

32. Miranda VS, Decarvalho VB, Machado LA, Dias JM. Prevalence of chronic musculoskeletal disorders in elderly Brazilians: a systematic review of the literature. BMC Musculoskelet Disord. 2012;13(1):82. https://doi.org/10.11 86/1471-2474-13-82.

33. Alonso Monteiro Bezerra M, Hellwig N, da Rocha Castelar Pinheiro G, Souza Lopes C. Prevalence of chronic musculoskeletal conditions and associated factors in Brazilian adults - National Health Survey. BMC Public Health. 2018; 18(1):287. https://doi.org/10.1186/s12889-018-5192-4.

34. Carroll LJ, Hogg-Johnson S, Côté P, van der Velde G, Holm LW, Carragee EJ, et al. Course and prognostic factors for neck pain in workers: results of the bone and joint decade 2000-2010 task force on neck pain and its associated disorders. J Manip Physiol Ther. 2009;32(2 Suppl):S108-16. https://doi.org/10.1016/j.jmpt.2008.11.015.

35. Fernández-de-las-Peñas C, Alonso-Blanco C, Hernández-Barrera V, PalaciosCeña D, Jiménez-García R, Carrasco-Garrido P. Has the prevalence of neck pain and low back pain changed over the last 5 years? A population-based national study in Spain. Spine J. 2013;13(9):1069-76. https://doi.org/10.1016/ j.spinee.2013.02.064.

36. Cohen SP. Epidemiology, diagnosis, and treatment of neck pain. Mayo Clin Proc. 2015;90(2):284-99. https://doi.org/10.1016/j.mayocp.2014.09.008.

37. Rao R. Neck pain, cervical radiculopathy, and cervical myelopathy: pathophysiology, natural history, and clinical evaluation. J Bone Joint Surg Am. 2002;84(10):1872-81. https://doi.org/10.2106/00004623-200210000-00021.

38. Ferreira Giovanni E. Buchbinder Rachelle, Zadro Joshua R, O'Keeffe Mary, Kharel Priti, Carballo-Costa Lidia, Oliveira Juliana S, Maher Christopher G, are musculoskeletal conditions neglected in national health surveys? Rheumatology. 2021. https://doi.org/10.1093/rheumatology.

39. Palmlöf $L$, Skillgate $E$, Alfredsson L, Vingård $E$, Magnusson $C$, Lundberg $M$, et al. Does income matter for troublesome neck pain? A population-based study on risk and prognosis. J Epidemiol Community Health. 2012;66(11): 1063-70. https://doi.org/10.1136/jech-2011-200783 Epub 2012 Mar 12.

40. Haldeman S, Carroll L, Cassidy JD, Schubert J, Nygren A. Bone and Joint Decade 2000-2010 Task Force on Neck Pain and Its Associated Disorders. The Bone and Joint Decade 2000-2010 Task Force on Neck Pain and Its Associated Disorders: executive summary. Spine (Phila Pa 1976). 2008;33(4 Suppl):S5-7. https://doi.org/10.1097/BRS.0b013e3181643f40.

41. https://www.researchgate.net/profile/Rodrigo-De-OliveiraAndrade/publica tion/335255226_Brazil\%27s_budget_cuts_threaten_more_than_80000_ science_scholarships/links/5d8d0f81299bf10cff12b36d/Brazils-budget-cutsthreaten-more-than-80-000-science-scholarships.pdf

42. Kim R, Wiest C, Clark K, Cook C, Horn M. Identifying risk factors for firstepisode neck pain: a systematic review. Musculoskelet Sci Pract. 2018:33:7783. https://doi.org/10.1016/j.msksp.2017.11.007 Epub 2017 Nov 22.
43. McLean SM, May S, Klaber-Moffett J, Sharp DM, Gardiner E. Risk factors for the onset of non-specific neck pain: a systematic review. J Epidemiol Community Health. 2010;64(7):565-72. https://doi.org/10.1136/jech.2009. 090720 Epub 2010 May 12

\section{Publisher's Note}

Springer Nature remains neutral with regard to jurisdictional claims in published maps and institutional affiliations.
Ready to submit your research? Choose BMC and benefit from:

- fast, convenient online submission

- thorough peer review by experienced researchers in your field

- rapid publication on acceptance

- support for research data, including large and complex data types

- gold Open Access which fosters wider collaboration and increased citations

- maximum visibility for your research: over $100 \mathrm{M}$ website views per year

At BMC, research is always in progress.

Learn more biomedcentral.com/submissions 